\title{
Hurricane Sandy Science Plan-Coastal Topographic and Bathymetric Data to Support Hurricane Impact Assessment and Response
}

"The understanding we gain from these studies will set the stage for better models addressing future hazard scenarios and will help coastal communities be better prepared to withstand and respond to catastrophic storms."-Suzette Kimball, U.S. Geological Survey Acting Director

\section{Meeting the Science Needs of the Nation in the Wake of Hurricane Sandy-A U.S. Geological Survey Science Plan for Support of Restoration and Recovery}

Hurricane Sandy devastated some of the most heavily populated eastern coastal areas of the Nation. With a storm surge peaking at more than 19 feet, the powerful landscape-altering destruction of Hurricane Sandy is a stark reminder of why the Nation must become more resilient to coastal hazards. In response to this natural disaster, the U.S. Geological Survey (USGS) received a total of \$41.2 million in supplemental appropriations from the Department of the Interior (DOI) to support response, recovery, and rebuilding efforts. These funds support a science plan (Buxton and others, 2013) that will provide critical scientific information necessary to inform management decisions for recovery of coastal communities, and aid in preparation for future natural hazards. This science plan is designed to coordinate continuing USGS activities with stakeholders and other agencies to improve data collection and analysis that will guide recovery and restoration efforts. The science plan is split into five distinct themes:

- Coastal topography and bathymetry

- Impacts to coastal beaches and barriers

- Impacts of storm surge, including disturbed estuarine and bay hydrology

- Impacts on environmental quality and persisting contaminant exposures

- Impacts to coastal ecosystems, habitats, and fish and wildlife

This fact sheet focuses on coastal topography and bathymetry.

\section{Stakeholders}

The U.S. Atlantic and Gulf coasts are vulnerable to hurricane impacts and lack the comprehensive integrated onshore/offshore baseline elevation data required to fully support hazard mitigation policies, redevelopment planning, and emergency preparedness and

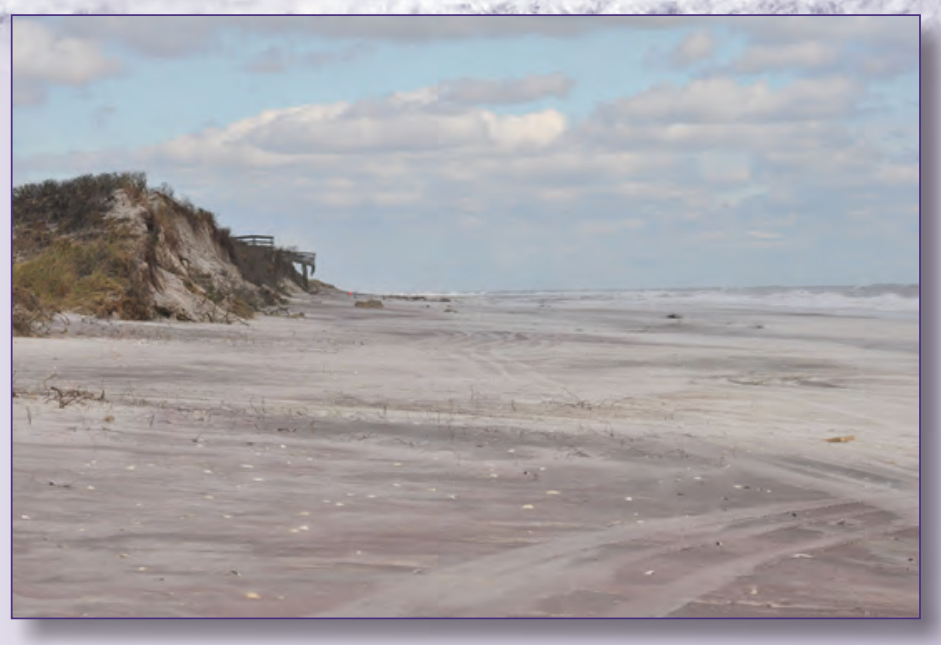

Dunes were severely eroded and the beach elevation lowered during the storm.

disaster response. These baseline data need to be accurate, up-todate, and readily available before a devastating hurricane affects one of these coastal areas. Post-Hurricane Sandy data are needed to guide recovery activities, to assess impacts, to forecast coastal vulnerability, and to establish the new baseline for future events and decisions. These data primarily are produced from lidar systems that are mounted on aircraft, a remote sensing technology used to make high-resolution maps of land features above and below the water, providing consistent and highly accurate information that is fundamental to numerous stakeholder needs.

The USGS, National Oceanic and Atmospheric Administration (NOAA), and the U.S. Army Corps of Engineers are using information from lidar flights, ships and satellites to survey coastal waters, shorelines and affected watersheds, acquiring data that will update East Coast topographic maps and nautical charts. The agencies will measure water depths, look for submerged debris, and record altered shorelines. The areas to be remapped will be based on their relative dangers to navigation, effects from the storm, and discussions with state and local officials as well as the maritime industry. The public 
domain data, managed by the USGS and NOAA, will be available to local, state, and federal agencies as well as academia and the general public. NOAA will make the coastal data and nautical charts available from the National Geophysical Data Center and the Digital Coast. USGS will make upland topographic data and bathymetric data available through The National Map. The information can be applied to updating nautical charts, removing marine debris, replenishing beaches, making repairs, watershed assessments, and planning for future storm and coastal resilience.

\section{Coastal Topography and Bathymetry Projects}

The fundamental lessons of Hurricane Sandy and prior catastrophic hurricanes are that storm vulnerability is first and foremost a consequence of coastal elevation. The height at which infrastructure, resources, and communities sit in relation to average tides and water levels, storm waves, surge, and flood waters determines their exposure to overwhelmingly powerful forces. Reliable, accurate and accessible elevation information is a priority for communities anticipating impacts and preparing response strategies. Post-storm elevation also is critical for design of resilient and cost-efficient post-storm redevelopment.

A key milestone in the National Ocean Policy Implementation Plan (National Ocean Council, 2012) calls for describing coastal and marine elevation throughout the United States and for improving coastal change analysis. To help accomplish this, the USGS will collect very high-resolution elevation data to support scientific studies related to the hurricane recovery and rebuilding activities, watershed planning and resource management. USGS will collect data in coastal and inland areas depending on their hurricane damages and the age and quality of existing data. The elevation data will become part of the 3D Elevation Program (3DEP), a USGS program to systematically acquire improved, high-resolution elevation data across the United States.

\section{Coastal National Elevation Dataset}

The USGS aims to create a Coastal National Elevation Dataset (CoNED) by compiling topographic and bathymetric elevation data from multiple sources. A CoNED for the entire Sandy impact region will be constructed to serve post-Hurricane Sandy recovery and other needs, including assessing coastal landscape change and vulnerability; designing restoration, redevelopment, and protection projects; predicting future hurricane storm surge and coastal and inland flooding; and devising strategies for climate change adaptation from sea-level rise and other effects.

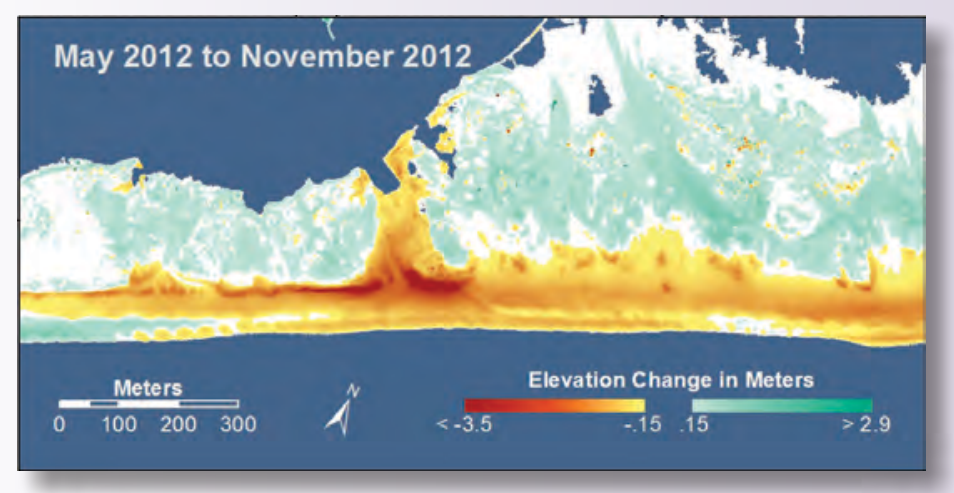

Elevation change on Pelican Island and Fire Island, New York, derived from lidar data.

\section{Delivery Systems for Hazards, Topographic, and Bathymetric Elevation Data}

Enhancements to the Hazards Data Distribution System (HDDS) and the 3DEP aim to improve Hurricane Sandy data delivery. Postevent disaster imagery collection can be expedited by combining near real-time hazard impact assessments with knowledge about populated areas. This improved system can ensure that data are delivered quickly and easily so that recovery and mitigation activities can be done effectively.

\section{Topographic Surveys for Impact Area Assessment and Reconstruction}

Topographic surveys will provide post-Sandy elevation data within the impact areas of Hurricane Sandy. The new data will be integrated with previously existing elevation data and made available through 3DEP. These data can be used to benefit post-Sandy recovery activities, including but not limited to emergency response assessment and planning, development of reconstruction plans, updating post-Sandy shoreline conditions, validation of storm-surge inundation predictions over urban areas, and supporting ecological assessments.

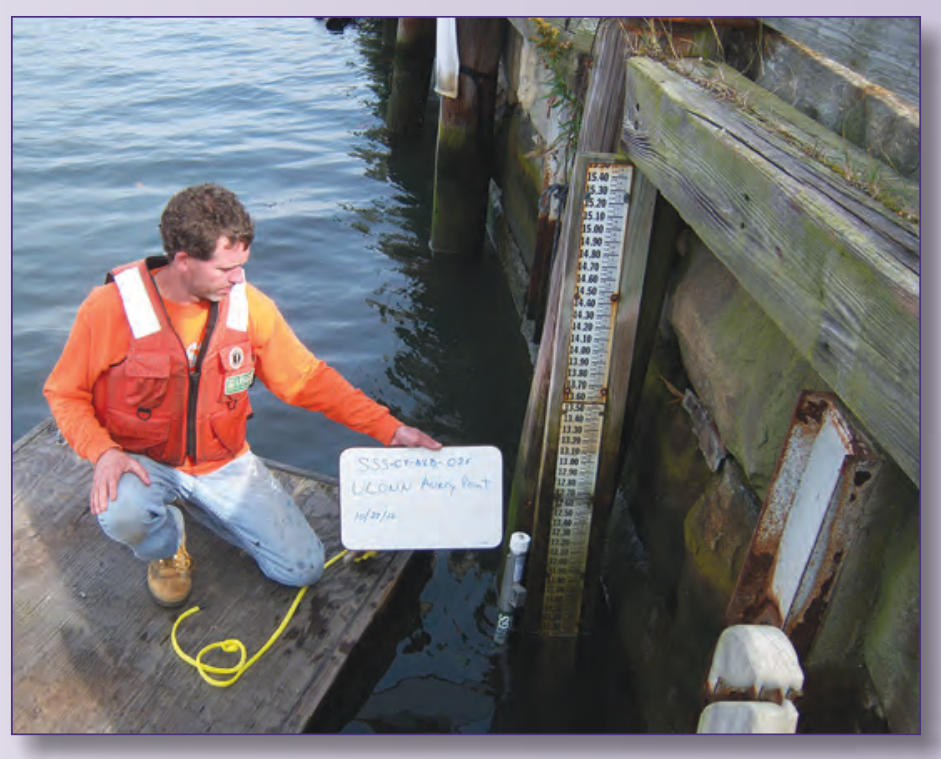

A U.S. Geological Survey scientist obtaining water-surface elevation data relative to a known reference elevation and deploying a stormtide sensor at SSS-CT-NLD-025 Poquonock River at Avery Point, Connecticut, October 27, 2012.

\section{For more information:}

Buxton, H.T., Andersen, M.E., Focazio, M.J., Haines, J.W., Hainly, R.A., Hippe, D.J., and Sugarbaker, L.J., 2013, Meeting the science needs of the Nation in the wake of Hurricane Sandy-A U.S. Geological Survey science plan for support of restoration and recovery: U.S. Geological Survey Circular 1390, 26 p., http://pubs.usgs.gov/circ/1390/.

National Ocean Council, 2012, National Ocean Policy Implementation Plan: Washington D.C., Executive Office of the President, $32 \mathrm{p}$.

- http://coastal.er.usgs.gov/hazard-events/sandy/ 